\title{
Pattern of fractures across pediatric age groups: analysis of individual and lifestyle factors
}

\author{
Giuliana Valerio ${ }^{1}$, Francesca Gallè ${ }^{1}$, Caterina Mancusi ${ }^{1}$, Valeria Di Onofrio ${ }^{1}$, Marianna Colapietro², Pasquale Guida², \\ Giorgio Liguori ${ }^{*}$
}

\begin{abstract}
Background: Knowledge of the epidemiology of children's fractures is essential to develop preventive strategies. The aim of this study was to analyze the individual/lifestyle determinants of fractures across pediatric age groups.

Methods: A cross-sectional study was performed in the first six months of 2008 through questionnaire on a sample of children from an outpatient clinic for pediatric fractures. Differences in gender, anatomic site, circumstances and location of fracture occurrence, behavioural lifestyle, and calcium intake were investigated among three different age classes (pre-school children, school children, and adolescents).

Results: The sample consisted of 382 subjects (2-14 years of age) sustaining a fracture after low or moderate trauma. Males were at a higher risk of fractures than females; greater than two-thirds of injuries occurred after lowenergy trauma and the upper limb was more frequently involved. With increasing age, the male/female ratio and time spent in sports participation increased $(p<0.001)$, while calcium intake and time spent in sedentary behaviors decreased ( $p<0.001$ and $<0.003$, respectively). Gender discordance existed in pre-school children with respect to the anatomic location, and in school children and adolescents with respect to the dynamics. In the adolescent group, males were more physically active and also more sedentary than females. Fractures most frequently occurred in homes (41.6\%), followed by playgrounds and footpaths (26.2\%), sports facilities (18.3\%), and educational facilities (13.9\%), with gender differences existing only in adolescence. Twenty-three percent of the subjects sustained one or more fractures in the past. The percentage of recurrent fractures increased with age $(p=$ 0.001), with a similar trend in both genders.

Conclusions: Gender differences were shown in the prevalence of injuries, characteristics, and circumstances across ages. These differences may be explained by the related changes in behaviors, together with attending different places. Individual and lifestyle factors can in part explain the variability in the occurrence of fractures and can also address targeted preventive strategies.
\end{abstract}

\section{Background}

Fractures are extremely common in the pediatric age group, representing a major public health problem. The lifetime risk of sustaining a fracture in childhood is approximately $42 \%-64 \%$ in boys and $27 \%-40 \%$ in girls, with remarkable variation in the estimates worldwide [1-4]. While fractures more often occur in males, girls usually sustain fractures at a younger age compared to boys [2-7]. Even though several genetic, endocrine, or systemic illnesses that affect bone metabolism may

\footnotetext{
* Correspondence: giorgio.liguori@uniparthenope.it

'School of Movement Sciences (DiSiST), Parthenope University, via Medina 40, 80133, Naples, Italy

Full list of author information is available at the end of the article
}

cause fractures, the majority of children with fractures are otherwise healthy. Several factors have been analyzed for their role in determining fracture risk. Bone mass and bone mineral density, low calcium intake, high body mass index (BMI), inactivity, behavioral difficulties, consumption of carbonated beverages, use of drugs (corticosteroids) have been variably associated with this kind of injury in children [7-11]. It has also been demonstrated that a first fracture at a young age is associated with an increasing risk of sustaining subsequent fractures $[12,13]$.

Studying the epidemiology of children's fractures is essential in developing preventive strategies. The importance of analyzing the etiology of injuries, and the

\section{Biomed Central}


circumstances and settings in which they occur in the various stages of development is to identify risky behaviors or an unsafe environment which can be corrected by specific preventive measures appropriate for age.

The purpose of this cross-sectional study was to analyze the individual and lifestyle determinants of fractures in a series of outpatient children and adolescents. Comparison of gender, anatomic site, circumstances and location of fracture occurrence, behavioural life style, and calcium intake were analysed among three different age classes (pre-school children, school children, and adolescents).

\section{Methods}

This was a cross-sectional study conducted in the outpatient clinic of the Department of Orthopedics and Traumatology of Santobono-Pausilipon Children Hospital in Naples (southern Italy). This hospital is the largest children's hospital in the Campania region, providing inpatient and outpatient services in emergency and trauma medicine in children $<14$ years of age within the metropolitan area of Naples. The study commenced on 1 January 2008 and was terminated on 30 June 2008. In 2008, the metropolitan area included 4,434,000 residents, of whom $17.3 \%$ (767,082 subjects) were $<14$ years of age. The investigation was approved by the Ethical Committee of the Santobono-Pausilipon Hospital and written informed consent was obtained from all participants and/or their parents or legal guardians in accordance with the revised version of the Helsinki Declaration regarding research involving human subjects.

The inclusion and exclusion criteria are reported in table 1 . Children < 2 years of age were not included because the analysis of lifestyle behaviors is hardly applicable at this very young age. The population was divided into 3 age ranges (pre-school children [2-5.9 years], school children [6.0-10.9 years], and adolescents [11-14 years]). Height and weight were measured and the BMI was calculated according to the following formula: (weight $[\mathrm{kg}] /$ height $\left[\mathrm{m}^{2}\right]$ ). Since BMI is age- and gender-related, this parameter was transformed into a standard deviation score (SDS), based upon the

\section{Table 1 Criteria for inclusion and exclusion of patients}

$\begin{array}{ll}\begin{array}{l}\text { inclusion } \\ \text { criteria }\end{array} & \text { age } \geq 2 \text { years } \\ & \text { resident in the Campania region } \\ \begin{array}{l}\text { exclusion } \\ \text { criteria }\end{array} & \text { fracture due to severe trauma } \\ & \begin{array}{l}\text { presence of any specific pathologic process known to } \\ \text { affect bone and mineral metabolism } \\ \text { presence of any specific treatment known to affect bone } \\ \text { and mineral metabolism }\end{array}\end{array}$

established Center for Disease Control normative curves [14]. Fractures were confirmed radiographically at the time of injury. Using information about each event documented in the medical record, fractures were classified based on their anatomic site, the location of the injury occurrence (home, playground, footpath, educational facility [kindergarten or school], and sports facility), and circumstances surrounding the fracture. Children were assigned to a trauma level category based on a modified Landin's description [15] that considers the height of the fall and the landing surface $[16,17]$, the physical activity engaged in, and whether or not any equipment was being used (Table 2). The occurrence of a previous accidental fracture confirmed by X-ray ascertained by the parents' report was elicited in the past history. The study also included a questionnaire assessment by parents regarding socioeconomic factors (parents' education) and some behavioural issues about the child, such as sports participation in the previous 12 months, weekly hours of sports activity, and daily hours of sedentary behaviours (sum of time spent in television viewing, computer, and video games). The total daily calcium intake was calculated using a food-frequency questionnaire, specifically established for a pediatric population [18]. The optimal daily calcium intake was defined according to the Italian Society for Human Nutrition guidelines [19].

\section{Statistical analysis}

The confidence interval estimation performed to determine the sample size indicated that a size of 127 produced a $99 \%$ confidence interval equal to the sample

\section{Table 2 Descriptive categories of Landin's modified} trauma levels (15)

Slight trauma
Falling to the ground from $<0.5 \mathrm{~m}$ (standing height)
Falling to a resilient surface (rubber or sand) from $0.5-3 \mathrm{~m}$
Falling from a bed or cot
Playing injuries, including playground scuffles
Low-energy sporting injuries, such as ball sports, judo, karate, wrestling,
and gymnastics
Moderate trauma
Falling to concrete or other non-resilient surface from $0.5-3 \mathrm{~m}$
Falling from a bunkbed
Baby being dropped to the floor by an adult
Falling downstairs
Falling from a bicycle
Falls while moving on skateboards, skis, rollerblades, or skates
Severe trauma
Falling from a height exceeding 3 m
All traffic accidents not already mentioned
Being hit by a moving heavy object


proportion plus or minus 0.05 when the estimated proportion was 0.05 (according to a recent estimated incidence of $5 \%$ of fractures in children $<14$ years of age [4]). All statistical analyses were carried out using the Statistical Package of Social Sciences (SPSS, Windows release 15.0; Chicago, IL, USA). A p value $<0.05$ was considered significant.

The results are reported as the mean $\pm \mathrm{SD}$. All of the continuous variables had a normal distribution, except for BMI-SDS, time spent in sports activities, and sedentary behaviors. Therefore, an independent sample t-test or a one-way ANOVA with a post hoc Bonferroni test were used for parametric variables, while the MannWhitney U test or the Kruskall-Wallis test were used for non-parametric variables. A chi-square test was used for categorical variables. Logistic regression analysis was performed to determine relationships between individual and lifestyle variables and fracture recurrence. The outcome variable was fracture recurrence, while the independent variables were gender (coded as 1 for boys and 2 for girls), age, BMI-SDS, adherence to calcium intake recommendations $(0=$ not adherent; $1=$ adherent $)$, time spent in sports activities, or in sedentary behaviours.

\section{Results}

Prevalence of fractures and lifestyle factors by age group and gender

Three-hundred eighty-two children were enrolled in the study. There were 261 boys $(68.3 \%)$ and 121 girls (31.7\%), with a mean age of $8.8 \pm 2.9$ years (range, 2-14 years). According to the age groups, there were 76 (19.9\%) pre-school children, 199 (52\%) school children, and $107(28.0 \%)$ adolescents. The demographic features are shown in Table 3. Males were at a higher risk of fracture than females in every age group, with a prevalence progressively increasing with age $(\mathrm{p}<0.001)$. No difference was found among the three age groups regarding BMI-SDS and parental educational level. The highest frequency of fractures occurred at 12 years of age in boys (15.3\%) and 9 years of age in girls (13.2\%); the lowest frequency of fractures occurred at 2 years of age in boys $(2.7 \%)$ and 3 years of age in girls $(2.5 \%)$. The percentage of subjects fulfilling the daily calcium recommendations significantly decreased with age (preschool children [86.8\%], school children [61.3\%], and adolescents [31.8\%], $\mathrm{p}<0.001)$, while weekly time spent in sports activities significantly increased (pre-school children $[0.38 \pm 0.83 \mathrm{hrs} /$ week], school children [1.73 \pm $2.3 \mathrm{hrs} /$ week], and adolescents [3.1 $\pm 3.1 \mathrm{hrs} /$ week], $\mathrm{p}<$ 0.001 ). The time spent in sedentary behaviors was significantly higher in adolescents $(5.6 \pm 2.9 \mathrm{hrs} /$ day) than pre-school children $(4.3 \pm 2.9 \mathrm{hrs} /$ day $)$ and school children $(4.7 \pm 2.8 \mathrm{hrs} /$ day; $\mathrm{p}<0.003)$. No gender difference
Table 3 Demographic features of subjects with fractures in the three age groups

\begin{tabular}{lccc}
\hline & $\begin{array}{c}\text { PRE-SCHOOL } \\
\text { CHILDREN }\end{array}$ & $\begin{array}{c}\text { SCHOOL } \\
\text { CHILDREN }\end{array}$ & ADOLESCENTS \\
\hline $\mathrm{N}$ & 76 & 199 & 107 \\
\hline Boys/girls n (ratio) & $42 / 34(1.2)$ & $128 / 71(1.8)$ & $91 / 16(5.7)^{* *}$ \\
\hline Age (years) & $4.38 \pm 1.1$ & $8.62 \pm 1.4$ & $12.29 \pm 0.8$ \\
\hline Height $(\mathrm{cm})$ & $113.3 \pm 11.5$ & $135.8 \pm 13.9$ & $152.8 \pm 16.9$ \\
\hline Weight $(\mathrm{kg})$ & $23.5 \pm 7.1$ & $38.3 \pm 11.28$ & $54.7 \pm 11.9$ \\
\hline BMl $\left(\mathrm{kg} / \mathrm{m}^{2}\right)$ & $18.3 \pm 4.3$ & $20.2 \pm 4.28$ & $22.9 \pm 4.1$ \\
\hline BMl- SDS & $0.93 \pm 2.0$ & $1.09 \pm 1.10$ & $1.16 \pm 0.99$ \\
\hline Father's education & & &
\end{tabular}

Father's education

level $n(\%)$

Elementary

Middle school

4 (6.1)

$22(11.7)$

$6(6.7)$

High school

29 (43.9)

80 (42.8)

41 (46.1)

Degree

$28(42.4)$

69 (36.9)

34 (38.2)

Mother's education

level n (\%)

Elementary

$5(7.6)$

$16(8.6)$

8 (9)

Middle school

$6(9.2)$

21 (11)

9 (10)

High school

24 (36.9)

$80(42.1)$

$39(43.3)$

Degree

$30(46.2)$

$78(41.1)$

30 (33.3)

** $\mathrm{p}<0.001$ pre-school children versus school children and adolescents; children versus adolescents

in any of these behaviors existed in pre-school children, while significant differences existed in both school children in whom males were more sedentary than girls $(\mathrm{p}$ $=0.001$ ), and in adolescents in whom males were more physically active $(\mathrm{p}<0.02)$ and more sedentary than girls $(\mathrm{p}=0.027$; Table 4).

\section{Dynamics of fractures}

The dynamics of fractures were known in 359 children (93.9\%). Fractures due to low-energy trauma occurred in 252 subjects (70.2\%). After stratification by gender and age class, low-energy trauma was more frequent in male school children and adolescents $(\mathrm{p}=0.007$ and $\mathrm{p}=$ 0.006 , respectively, table 3 ), while no difference existed in pre-school children.

\section{Anatomic sites of fractures}

The prevalence of fractures according to the anatomic site is shown in table 5. Except for two cases of clavicular fractures, the near totality of injuries involved the upper (84.1\% cases) or lower limb (15.9\%). The net prevalence of the upper limb over the lower limb was independent of age group. A slight gender discordance existed only in pre-school children in whom upper limb fractures were more frequent in boys than girls $(\mathrm{p}=$ 0.054). A further distinction based on upper arm, forearm and wrist, and hand showed significant differences 
Table 4 Gender comparison of the characteristics of fractures, and nutritional and behavioural habits in the three age groups

\begin{tabular}{lccccccccc}
\hline & \multicolumn{2}{c}{ PRE-SCHOOL CHILDREN } & \multicolumn{2}{c}{ SCHOOL CHILDREN } & \multicolumn{3}{c}{ ADOLESCENTS } \\
\hline & Males & Females & $\boldsymbol{p}$ & Males & Females & $\boldsymbol{p}$ & Males & Females & $\boldsymbol{p}$ \\
\hline Low energy trauma (\%) & 66.7 & 61.3 & 0.635 & 79.8 & 61.8 & 0.007 & 72.6 & 30.0 & 0.006 \\
\hline Upper limb (\%) & 91.7 & 74.2 & 0.054 & 86.9 & 86.4 & 0.920 & 79.5 & 75.0 & 0.723 \\
\hline Adherence to calcium intake recommendations (\%) & 83.8 & 90.6 & 0.400 & 59.0 & 65.2 & 0.398 & 31.8 & 33.3 & 0.904 \\
\hline Sports participation (hours/week) & $0.4 \pm 0.9$ & $0.3 \pm 0.7$ & 0.413 & $1.6 \pm 1.9$ & $2.0 \pm 2.9$ & 0.173 & $3.4 \pm 3.2$ & $1.7 \pm 2.7$ & 0.043 \\
\hline $\begin{array}{l}\text { Sedentary behaviours } \\
\text { (hrs per day) }\end{array}$ & $4.4 \pm 3.2$ & $4.2 \pm 2.5$ & 0.735 & $5.2 \pm 2.9$ & $3.7 \pm 2.1$ & 0.001 & $5.9 \pm 3.0$ & $4.1 \pm 2.1$ & 0.020 \\
\hline
\end{tabular}

between genders only in pre-school children $(\mathrm{p}=0.001)$ in whom the upper arm was predominantly involved in girls $(73.9 \%)$ and the forearm and wrist in boys (63.6\%).

\section{Locations of fracture occurrences}

The home was the main location ( $\mathrm{n}=159$ [41.6\%]), followed by the playground and footpath ( $\mathrm{n}=100$ [26.2\%]), sports facility $(\mathrm{n}=70[18.3 \%])$, and educational facility $(n=53[13.9 \%])$. Location was separately analyzed by gender and age. In males the percentage of fractures occurring in the home significantly decreased with age, while the percentage of fractures occurring in educational facilities, playgrounds and footpaths, or in sports facilities increased ( $\mathrm{p}<0.001$; Figure 1, panel A). In females the home represented the most frequent location at any age, while fractures in the playground and footpath or sports facility significantly decreased with age ( $p=0.026$; Figure 1 , panel $B$ ) and a U-shaped curve was observed regarding educational facilities. No difference between genders existed in each age group, except in adolescents, in whom the playground and footpath was the location more frequently reported by males $(33.0 \%)$ and the home was more frequently reported by females $(43.8 \%, \mathrm{p}=0.048)$.

Table 5 Distribution of fractures among the different sites

\begin{tabular}{ccc}
\hline & number & $\%$ \\
\hline Distal radius and physis & 116 & 30.4 \\
\hline Radial shaft & 92 & 24.1 \\
\hline Elbow area (distal humerus, proximal radius, and ulna) & 70 & 18.3 \\
\hline Humerus (proximal and shaft) & 33 & 8.6 \\
\hline Hand (carpals, metacarpals, and phalanges) & 8 & 2.1 \\
\hline Clavicle & 2 & 0.5 \\
\hline Tibial shaft & 22 & 5.8 \\
\hline Foot (metatarsal and phalanges) & 17 & 4.4 \\
\hline Ankle (distal tibia) & 16 & 4.2 \\
\hline Femur (neck and shaft) & 5 & 1.3 \\
\hline Other & 1 & 0.2 \\
\hline
\end{tabular}

\section{Recurrent fractures}

Eighty-eight subjects (23.2\%) sustained one or more fractures in the past that were ascribed by parents to accidental injuries. The percentage of recurrent fractures increased from pre-school children to adolescents (from $7.9 \%$ to $40.6 \%, \mathrm{p}=0.001$ ), with a similar trend in both genders. Subjects with recurrent fractures did not differ from those reporting only one fracture with respect to BMI-SDS, time spent in sports activities, or sedentary behaviors (data not shown). Fractures caused by lowenergy trauma occurred in $74.7 \%$ of subjects with recurrent fractures and $68.7 \%$ of subjects reporting only one fracture ( $p$ not significant). Fifty-six percent of subjects with recurrent fractures did not fulfill the daily recommendations of calcium intake in comparison with $37 \%$ of subjects who reported only one fracture $(p=0.001)$. In order to exclude confounders, logistic regression analysis was used in which recurrence of fractures was the independent variable and age, gender, BMI-SDS, adherence to daily calcium intake recommendations, weekly time spent in sports activities, and daily time spent in sedentary behaviors were the dependent variables. Only older age was independently associated with recurrent fractures $[\operatorname{Exp}(B), 1.287 ; 95 \% \mathrm{CI}, 1.146-1.445, \mathrm{p}<0.001$, table 6].

\section{Discussion}

It has been reported that fractures are a common event in childhood [1-3], with considerable variations in the incidence rate from $1.2 \%$ to $5 \%$ among different studies $[4,20,21]$. This variability may depend on the child's condition, age, and social and environmental factors. Few data are available regarding the epidemiology of fractures in the various periods of pediatric ages [21]. These periods are characterized by different stages of physical, cognitive and social development, and may obviously explain the varying pattern of injuries across age groups $[21,22]$. We enrolled a population of patients receiving treatment for fractures caused by slight or moderate dynamics. In order to describe possible differences among the various developmental stages and define individual and lifestyle determinants of fractures 

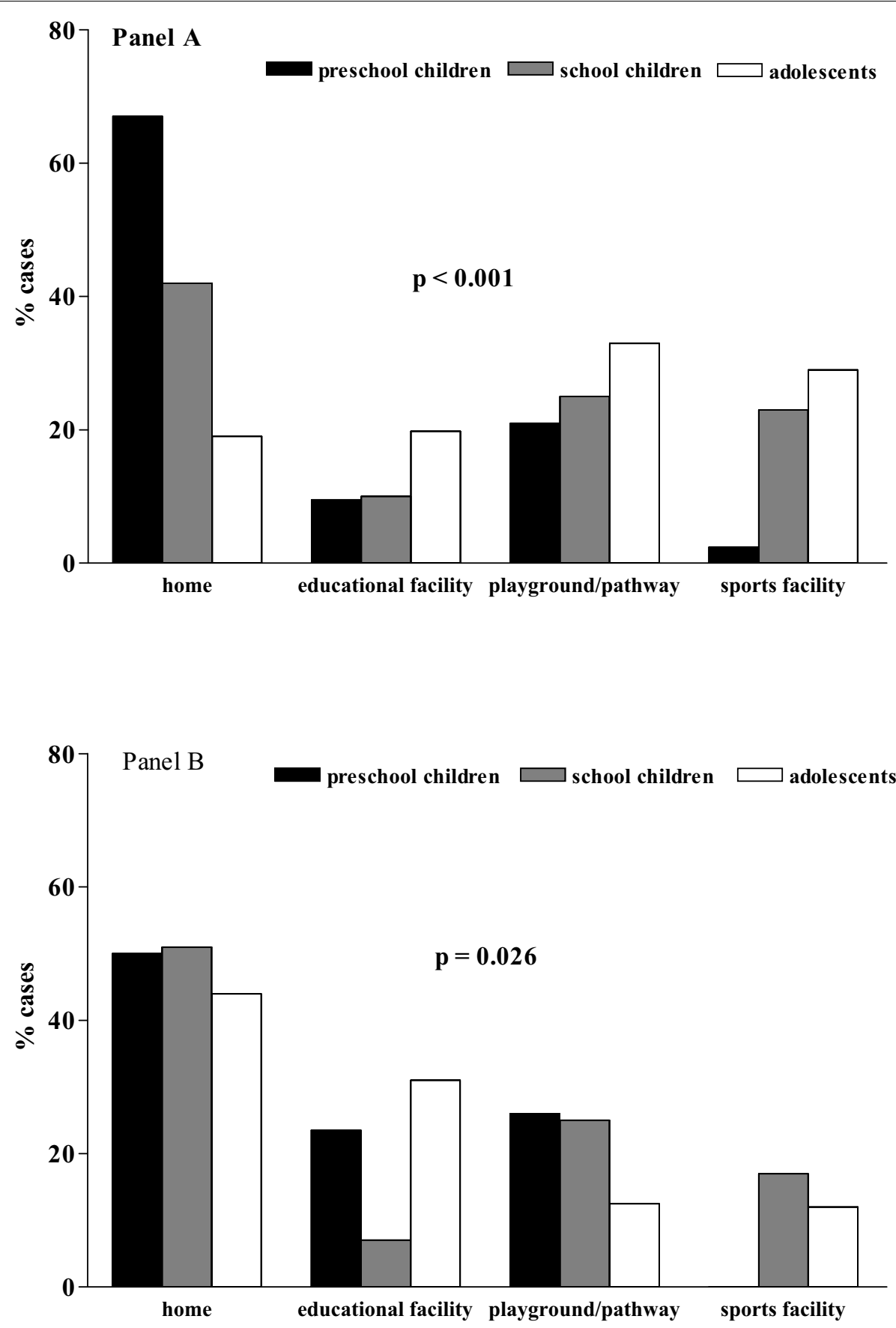

Figure 1 Main locations of injury in the different age groups (panel A, boys; panel B, girls).

according to age, this population was divided in preschool children, school children, and adolescents. Our data indicate that males were at higher risk of fractures than females, more than two-thirds of injuries occurred after low-energy trauma, and the upper limb was more frequently involved. With increasing age, the male/ female ratio and time spent in sports participation increased, while calcium intake and time spent in sedentary behaviors decreased. A gender discordance was demonstrated in pre-school children with respect to the anatomic location and in school children and adolescents with respect to the dynamics. In the adolescent group, males were not only physically more active than females, but also more sedentary. Gender differences in the incidence of fractures in the pediatric age group are well-known. The overall percentage of children from 0 - 
Table 6 Variables independently associated with age at fracture occurrence by multiple regression analysis in the entire sample of patients

\begin{tabular}{llll}
\hline $\begin{array}{l}\text { Independent Variable: } \\
\text { Age at fracture occurrence }\end{array}$ & & & \\
\hline Dependent variables & $\begin{array}{l}\text { B } \\
\text { Coefficients }\end{array}$ & SE & p \\
\hline Gender (1 = Male, 2 = Female) & -.683 & 0.29 & .018 \\
BMI-SDS & 0.208 & 0.10 & .042 \\
Calcium intake (0 = not adherent, 1 & -2.218 & 0.27 & .000 \\
adherent) & & & \\
Sports activities (hrs/week) & 0.357 & 0.05 & 0.000 \\
Sedentary behaviors (hrs/day) & 0.166 & 0.05 & .001 \\
\hline
\end{tabular}

16 years of age sustaining at least 1 fracture is higher (42\%) in boys than girls (27\%) [23,24], and the peak incidence is roughly 3 years earlier in girls than boys (11 and 14 years, respectively) [3]. Similarly, our data confirmed that the overall fracture prevalence was higher in boys, independent of age, but the peak frequency occurred 2 years earlier than previous studies reported (9 years in girls and 12 years in boys). The increase in fracture rate during the pubertal years has been explained by a discrepancy between height gain and the accrual of bone mineralization [25]. Since the onset of puberty progressively anticipated in the last century in several European countries, including Italy [26], the 2year anticipation of the peak frequency of fractures may be explained by the earlier peak height velocity associated with pubertal growth. We found that the maleto-female ratio significantly increased from pre-school children (1.2) to adolescents (5.7) in agreement with previous reports $[27,28]$. We did not find any difference in the parental educational level among the three age classes. The relationship between socioeconomic status and the risk of fractures has been analyzed with contradictory evidence. While unintentional home injuries in pre-school children is related to the main caregiver's level of education [29], no clear evidence of a socioeconomic gradient in the total incidence of fractures has been shown in childhood $[8,15,30,31]$. Interestingly, Williams et al. [32] reported that parental socioeconomic status was related to the circumstances in which injury events occurred in adolescents, influencing the extent and type of the risk behaviours. Seasonal variation in the incidence of pediatric fractures has been reported in several studies, with the highest peak found in the warmer months [21,33]. Subjects in our investigation were enrolled in the first 6 months of the year. A full-year review would have been valuable in order to exclude a possible enrollment bias; however, the weather in our region does not substantially influence behaviours during leisure time. Moreover, the admissions for fractures were equally distributed in the first and second semesters of the year according to the hospital report.

We showed that in $77 \%$ of cases fractures were ascribed to low-energy trauma (mainly falls) that occurred more frequently in males in school children and adolescents. Similarly, Rennie et al. [21], who analyzed the basic epidemiology for different mechanisms of fracture in British children, reported that falls accounted for $57 \%$ of all fractures, occurred at a younger age and prevailed in males.

Increased participation in both organized and informal sports, as well as the overall high levels of physical activity during adolescence, has been previously advocated to explain the increased incidence of fractures in adolescents [21,34-36]. In particular, gender difference in the incidence of injuries may be explained by age-related changes in behaviors, such as participation in activities with increased physical risks by males [37]. In a population-based case control study, Ma and Jones [6] reported that participation in sports increased the risk of upper limb fractures in boys and decreased the risk of upper limb fractures in girls, even for the same sport. This effect was independent of bone mass, suggesting gender heterogeneity in the approach to sports, and implies that the beneficial effect of physical activity on bone health $[38,39]$ can be hindered in males, who probably are engaged in physical activities with higher potential for trauma. Indeed the relationship between physical activity, bone mass, and childhood fracture risk is complex. A positive association between vigorous physical activity and childhood fractures that was independent of bone mass was demonstrated by Clark et al. [15]. Participation in vigorous physical activity or contact sport may increase bone mass, but does not protect from the risk caused by increased exposure to injuries. The influence of physical activity on fracture risk is determined by its net effect on fall-related trauma and bone strength. Therefore, as motor ability increases, the involvement in physical activities increases and the risk of injuries increases, particularly in boys [40]. In agreement with these previous reports, we found that adolescents sustaining a fracture spent higher amounts of time in organized physical activity than their counterparts in pre-school children or school children; in addition, males were more physically active and sedentary than females. A previous study reported a dose response association between time spent in television, computer, and video viewing and wrist and forearm fracture risk in both genders [6]. It would be expected that sedentary behaviours would reduce levels of physical activity and consequently lower the risk of trauma. Indeed, several studies have not demonstrated any negative relationship between video exposition and moderate or vigorous leisure-time physical activity, indicating that these 
behaviours may co-exist [41]. The increased time spent watching television or playing computer games may lead to unhealthy behaviours, such as increased consumption of energy-dense snack foods or carbonated beverages, obesity, or aggressive behaviour, conditions that may place children at greater risk of fractures $[42,43]$.

Regarding the anatomic site, the upper limb is more frequently involved in pediatric fractures, accounting for approximately two-thirds of all fractures [20]. We confirmed that the upper limb was more frequently involved at any age, representing indeed $>80 \%$ of fractures, in agreement with a previous epidemiologic study performed in various age groups [21]. This higher prevalence may be explained by the fact that $77 \%$ children in our study reported low-energy fractures, the main cause being represented by falls. Indeed, the arm is more frequently involved after a fall in children $>5$ years of age [44]. In pre-school children, the upper limb was involved in $92 \%$ of cases in boys and $74 \%$ of cases in girls, despite no difference in dynamics between genders. This finding is in agreement with a larger survey on the incidence pattern for different fracture sites by age and gender in which sexual dimorphism existed for fractures of the tibia/fibula [3]; in fact, a higher incidence of fractures at this site existed in girls $<6$ years of age and in boys $>14$ years of age. Age-related differences at the upper site have been also described; specifically, humeral fractures tend to peak first (6-7 years in both genders) followed by radius-ulna fractures (10-11 years in girls and 12-13 years in boys), while carpal fractures peak later (12-13 years in girls and 14-15 years in boys). We found that the frequency of upper arm, forearm and wrist, and hand fractures differed between genders only in pre-school age children, when females predominantly sustained upper arm fractures (73.9\%) and boys sustained forearm and wrist fractures (63.6\%). These discrepancies can probably be explained by different specific causes related to fall characteristics.

Regarding the locations where fractures commonly occur, it has been reported that the home accounts for $37 \%$ of all fractures in children, while the school represents $20 \%$ [23]. In our experience as well, the home was the place where fractures most frequently occurred, and locations changed among age groups and gender. These findings are not surprising and reflect the amount of time that pre-school children spend at home in comparison with older children and adolescents who gradually spend a greater amount of their active time outside the home [22]. Significant differences between genders were found only in adolescents $(p=0.048)$ because boys mainly sustained fractures in the playgrounds and footpaths and girls sustained fractures at home.

It is well-known that children who experienced one fracture tend to be at increased risk of repeated fractures $[12,13]$ and have lower bone mineral density and accretion than their peers $[9,45,46]$. We found that $23.2 \%$ of otherwise healthy children sustained one or more previous fractures, with an increasing percentage from pre-schoolers to adolescents (from $7.9 \%$ to $40.6 \%$, $\mathrm{p}=0.001)$ and no difference between genders. This fact is not surprising, since with increasing age there is a longer exposure time for injuries. We excluded underlying pathology or chronic illnesses that may have predisposed the subjects to reduced bone mineralization, although we could not determine whether or not these children were "accident prone," or lived in a dangerous environment. No one was suspected to be victim of physical abuse. Insufficient calcium intake was found in a large number of children with recurrent fractures. Indeed, low calcium intake has been linked with decreased bone density and fracture risk in children. Children who sustained repeated fractures had total body and lumbar spine bone size and mass significantly lower than controls; they also had a significantly lower intake of milk, lower levels of physical activity, a higher BMI, and a higher consumption of carbonated beverages [9]. We found that the association with low calcium intake disappeared in logistic linear regression analysis, where only age was independently associated with fracture recurrence. Therefore, in our sample, the association of low calcium intake with recurrent fractures was primarily mediated by age.

\section{Conclusions}

The differences which existed in the prevalence of injuries, characteristics, and circumstances across the three age groups may be explained by age- and gender-related changes in behaviors, together with attending different places. Individual and lifestyle factors ascribed to either higher sports activities or sedentary behaviors can in part explain the variability in the occurrence of fractures in older age. The incidence of paediatric fractures can be reduced with public education, implementation of safety strategies, and government legislation. Health care professionals and paediatricians can be instrumental in reducing the incidence of paediatric injuries by participating in child education, research, and programs that promote safe play.

\section{Author details}

${ }^{1}$ School of Movement Sciences (DiSiST), Parthenope University, via Medina 40, 80133, Naples, Italy. ${ }^{2}$ Department of Orthopaedics and Traumatology, Santobono-Pausilipon Children Hospital, via Mario Fiore 4, 80129 Naples, Italy.

Authors' contributions

GV, PG, and GL provided substantial contributions to the conception and design of the study, definition of the objectives, development of the questionnaire, and analysis and interpretation of data; they revised the paper 
critically for important intellectual content and gave their final approval of the version to be published.

GV, FG, and VDO provided substantial contributions to background analysis and literature research, analysis, and interpretation of data, drafting the manuscript, and gave their final approval of the version to be published. $\mathrm{CM}$ and $\mathrm{MC}$ provided substantial contributions to acquisition of data, parent interviews, and development of the database; they inputted the data in dedicated software, contributed to drafting the manuscript, and gave their final approval of the version to be published.

\section{Competing interests}

The authors declare that they have no competing interests.

Received: 5 June 2010 Accepted: 30 October 2010

Published: 30 October 2010

\section{References}

1. Landin LA: Fracture patterns in children. Analysis of 8,682 fractures with special reference to incidence, etiology and secular changes in a Swedish urban population 1950-1979. Acta Orthop Scand Suppl 1983, 202:1-109.

2. Jones IE, Williams SM, Dow N, Goulding A: How many children remain fracture-free during growth? a longitudinal study of children and adolescents participating in the Dunedin Multidisciplinary Health and Development Study. Osteoporos Int 2002, 13:990-995.

3. Cooper C, Dennison EM, Leufkens HG, Bishop N, van Staa TP: Epidemiology of childhood fractures in Britain: a study using the general practice research database. J Bone Miner Res 2004, 19:1976-1981.

4. Donaldson LJ, Reckless IP, Mindell JS, Shelton NJ: The epidemiology of fractures in England. J Epidemiol Community Health 2008, 62:174-180.

5. Khosla S, Melton LJ, Dekutoski MB, Achenbach SJ, Oberg AL, Riggs BL: Incidence of Childhood Distal Forearm Fractures Over 30 Years: A Population-Based Study. JAMA 2003, 290:1479-1485.

6. Ma D, Jones G: Television, computer, and video viewing; physical activity; and upper limb fracture risk in children: a population-based case control study. J Bone Miner Res 2003, 18:1970-1977.

7. Goulding A, Rockell JE, Black RE, Grant AM, Jones IE, Williams SM: Children who avoid drinking cow's milk are at increased risk for prepubertal bone fractures. Am Diet Assoc 2004, 104:250-253.

8. Hallal PC, Siqueira FV, Menezes AM, Araújo CL, Norris SA, Victora CG: The role of early life variables on the risk of fractures from birth to early adolescence: a prospective birth cohort study. Osteoporos Int 2009, 20:1873-1879.

9. Manias K, McCabe D, Bishop N: Fractures and recurrent fractures in children; varying effects of environmental factors as well as bone size and mass. Bone 2006, 39:652-657.

10. Goulding A: Risk factors for fractures in normally active children and adolescents. Med Sport Sci 2007, 51:102-120.

11. Loder RT, Warschausky S, Schwartz EM, Hensinger RN, Greenfield ML: The psychosocial characteristics of children with fractures. J Pediatr Orthop $1995,15: 41-46$

12. Goulding A, Jones IE, Williams SM, Grant AM, Taylor RW, Manning PJ, Langley J: First fracture is associated with increased risk of new fractures during growth. J Pediatr 2005, 146:286-288.

13. Yeh FJ, Grant AM, Williams SM, Goulding A: Children who experience their first fracture at a young age have high rates of fracture. Osteoporos Int 2006, 17:267-272.

14. Kuczmarski RJ, Ogden CL, Guo SS, Grummer-Strawn LM, Flegal KM, Mei Z, Wei R, Curtin LR, Roche AF, Johnson CL: 2000 CDC Growth Charts for the United States: methods and development. Vital Health Stat 11 2002, 246:1-190

15. Clark EM, Ness AR, Tobias JH: Bone fragility contributes to the risk of fracture in children, even after moderate and severe trauma. J Bone Miner Res 2008, 23:173-179.

16. Hansoti B, Beattie T: Can the height of fall predict long bone fracture in children under 24 months? Eur J Emerg Med 2005, 12:285-286.

17. Chalmers DJ, Marshall SW, Langley JD, Evans MJ, Brunton CR, Kelly A-M, Pickering AF: Height and surfacing as risk factors for injury in falls from playground equipment: a case-control study. Injury Prevention 1996, 2:98-104.
18. Esposito-del Puente A, del Puente A, Scalfi L, Covino A, Marra M, Contaldo F: Calcium intake in a childhood population showing high prevalence of obesity. Int J Obes Relat Metab Disord 1997, 21(Suppl 84).

19. Società Italiana di Nutrizione Umana: LARN. Livelli di assunzione raccomandati di energia e nutrienti per la popolazione italiana Milan: EDRA; 1996.

20. Jones G: Growth, children, and fractures. Curr Osteoporos Rep 2004, 2:75-78.

21. Rennie L, Court-Brown CM, Mok JY, Beattie TF: The epidemiology of fractures in children. Injury 2007, 38:913-922.

22. Maclnnes K, Stone DH: Stages of development and injury: an epidemiological survey of young children presenting to an emergency department. BMC Public Health 2008, 8:120.

23. Rockwood CA, Wilkins KE: Fractures in children. Philadelphia: Lippincott Williams and Wilkins; 2006.

24. Brinker MR, O'Connor DP: The incidence of fractures and dislocations referred for orthopaedic services in a capitated population. J Bone Joint Surg Am 2004, 86:290-297.

25. Bailey DA, Wedge JH, McCulloch RG, Martin AD, Bernhardson SC: Epidemiology of fractures of the distal end of the radius in children as associated with growth. J Bone Joint Surg Am 1989, 71:1225-1231.

26. Castellino N, Bellone S, Rapa A, Vercellotti A, Binotti M, Petri A, Bona G: Puberty onset in Northern Italy: a random sample of 3597 Italian children. J Endocrinol Invest 2005, 28:589-594.

27. Cheng JC, Shen WY: Limb fracture pattern in different pediatric age groups: a study of 3,350 children. J Orthop Trauma 1993, 7:15-22.

28. Cheng JC, Ng BK, Ying SY, Lam PK: A 10-year study of the changes in the pattern and treatment of 6,493 fractures. J Pediatr Orthop 1999, 19:344-350.

29. Ramsay L, Moreton G, Gorman DR, Blake E, Goh D, Elton RA, Beattie TF: Unintentional home injury in preschool-aged children: looking for the key-an exploration of the inter-relationship and relative importance of potential risk factors. Public Health 2003, 117:404-411.

30. Lyons RA, Delahunty AM, Heaven M, McCabe M, Allen H, Nash P: Incidence of childhood fractures in affluent and deprived areas: population based study. BMJ 2000, 320:1276-1277.

31. Stark AD, Bennet GC, Stone DH, Chishti P: Association between childhood fractures and poverty: population based study. BMJ 2002, 324:457.

32. Williams JM, Currie CE, Wright P, Elton RA, Beattie TF: Socioeconomic status and adolescent injuries. Soc Sci Med 1997, 44:1881-1891.

33. Wareham K, Johansen A, Stone MD, Saunders J, Jones S, Lyons RA: Seasonal variation in the incidence of wrist and forearm fractures, and its consequences. Injury 2003, 34:219-222.

34. Tiderius CJ, Landin L, Düppe H: Decreasing incidence of fractures in children: an epidemiological analysis of 1,673 fractures in Malmö, Sweden, 1993-1994. Acta Orthop Scand 1999, 70:622-626.

35. Bijur PE, Trumble A, Harel Y, Overpeck MD, Jones D, Scheidt PC: Sports and recreation injuries in US children and adolescents. Arch Pediatr Adolesc Med 1995, 149:1009-1016.

36. Landin LA: Epidemiology of children's fractures. J Pediatr Orthop B 1997, 6:79-83.

37. Rivara FP, Bergman AB, LoGerfo JP, Weiss NS: Epidemiology of childhood injuries. II. Sex differences in injury rates. Am J Dis Child 1982, 136:502-506.

38. Slemenda CW, Millet JZ, Hui SL, Reister TK, Johnston CC Jr: Role of physical activity in the development of skeletal mass in children. J Bone Miner Res 1991, 11:1227-1233.

39. Cooper C, Cawley M, Bhalla A, Egger P, Ring F, Morton L, Barker D: Childhood growth, physical activity, and peak bone mass in women. $J$ Bone Miner Res 1995, 10:940-947.

40. Gofin R, Donchin M, Schulrof B: Motor ability: protective or risk for school injuries? Accid Anal Prev 2004, 36:43-48.

41. Taveras EM, Field AE, Berkey CS, Rifas-Shiman SL, Frazier AL, Colditz GA, Gillman MW: Longitudinal relationship between television viewing and leisure-time physical activity during adolescence. Pediatrics 2007, 119:314-319.

42. Ma D, Jones G: Soft drink and milk consumption, physical activity, bone mass, and upper limb fractures in children: a population-based casecontrol study. Calcif Tissue Int 2004, 75:286-291. 
43. Johnson JG, Cohen P, Smailes EM, Kasen S, Brook JS: Television viewing and aggressive behavior during adolescence and adulthood. Science 2002, 295:2468-2471.

44. Pitone ML, Attia MW: Patterns of injury associated with routine childhood falls. Pediatr Emerg Care 2006, 22:470-474.

45. Ferrari SL, Chevalley T, Bonjour JP, Rizzoli R: Childhood fractures are associated with decreased bone mass gain during puberty: an early marker of persistent bone fragility? J Bone Miner Res 2006, 21:501-507.

46. Goulding A, Jones IE, Taylor RW, Williams SM, Manning PJ: Bone mineral density and body composition in boys with distal forearm fractures: a dual-energy x-ray absorptiometry study. J Pediatr 2001, 139:509-515.

\section{Pre-publication history}

The pre-publication history for this paper can be accessed here: http://www.biomedcentral.com/1471-2458/10/656/prepub

doi:10.1186/1471-2458-10-656

Cite this article as: Valerio et al:: Pattern of fractures across pediatric age groups: analysis of individual and lifestyle factors. BMC Public Health $201010: 656$

\section{Submit your next manuscript to BioMed Central} and take full advantage of:

- Convenient online submission

- Thorough peer review

- No space constraints or color figure charges

- Immediate publication on acceptance

- Inclusion in PubMed, CAS, Scopus and Google Scholar

- Research which is freely available for redistribution

Submit your manuscript at www.biomedcentral.com/submit 